\title{
An experimental set-up for real-time continuous moisture measurements of plywood exposed to outdoor climate
}

Jan Van den Bulcke ${ }^{1 *}$, Joris Van Acker ${ }^{1}$, Jordi De Smet ${ }^{1}$

${ }^{1}$ Ghent University, Laboratory of Wood Technology, Faculty of Bioscience Engineering, Coupure Links 653, 9000 Gent, Belgium

${ }^{*}$ corresponding author e-mail: Jan.VandenBulcke@UGent.be;

tel: + $0032(0) 926461$ 24; fax: + $0032(0) 92646233$

\section{Cite as:}

Van den Bulcke, J., Van Acker, J. De Smet, J. (2009a). An experimental set-up for real-time continuous moisture measurements of plywood exposed to outdoor climate. Building and Environment, 44(12), 2368-2377.

http://dx.doi.org/10.1016/j.buildenv.2009.03.021 


\begin{abstract}
Plywood used in exterior conditions is prone to water uptake and release. The influence of moisture on the strength properties and the decay risk is substantial. Therefore it is crucial to gather knowledge on the moisture behaviour of plywood in service, especially considering the fact that the intrinsic durability of the wood species used, is not exclusively determining outdoor performance. An automatic measurement set-up is proposed. The concept relies on a logger system recording the weight of plywood samples mounted on calibrated load cells. Mass changes are attributed to changes in moisture content induced by monitored environmental conditions such as solar irradiation, wind, rain and relative humidity. Pre- and post-processing of 10 plywood types is elaborated on. Logically, the length of a rain event has an influence on the moisture content of plywood. Differences in moisture dynamics of different plywood types are attributed to veneer thickness, glue type and wood species and their susceptibility to weathering. Further straightforward correlation was found between plywood moisture content, temperature and relative humidity. Time of wetness calculation based on these data illustrates the moisture dynamics of plywood and is a potential basis for service life prediction of plywood.
\end{abstract}

Keywords: continuous moisture measurements; plywood; data processing; time of wetness 


\section{Introduction}

Wood is intensively used in the building industry as a construction material. Its sustainability is an advantage opposed to non-renewable resources such as aluminium, steel, concrete and plastics. The use of wood as a construction material in general results in lower energy and $\mathrm{CO}_{2}$ balances than when concrete is used [1]. A lot of construction material consists of engineered wood products. As such, the intrinsic variability is levelled out, precise specifications are met and by-products of wood manufacturing can be processed. An important representative of this group of materials is plywood showing excellent physical and mechanical properties.

Nowadays, a broad range of plywood applications consists of use class 3 situations (facades elements, cornices, concrete shuttering, advertisements boards...) where the plywood is subject to natural weathering [2]. The conditions for these situations are defined in EN 335 [3] whereas the requirements for plywood are identified in EN 636 [4]. Typically, in such an outdoor out of ground application, plywood is not continuously wet but can be subject to frequent wetting and drying subsequent. It is generally known that moisture has a significant influence on the mechanical and physical properties of wood, plywood and other wood based materials [5], [6] and [7]. As wood based panels are hygroscopic and since their surface to volume ratio is very high, physical deformations and cracks are possible. In the case of plywood the strength properties of the glue lines are affected by changing moisture, resulting in a risk of delamination and panel failure [8]. Finally moisture can initiate fungal growth and biological deterioration. Whereas moulds and blue stain fungi are mainly surface spoilers, rot fungi can actively break down the substrate. Especially the latter are important in order to estimate the decay risk, setting a limit of $25 \%$ moisture content as a critical factor [9] which more or less matches the FSP (Fibre Saturation Point) of wood. Once established, fungi can survive low moisture contents in an inactive state, while reactivating quickly under suitable conditions [10]. Although wood durability normally determines outdoor use, plywood of non-durable wood species can perform satisfactory. Therefore other measures of performance, independent of the intrinsic durability of the wood species, are necessary. Moisture behaviour of solid wood products in exterior applications, both simulations and in-situ applications has already been studied 
extensively [11], [12], [13], [14], [15] and [16]. For plywood far less research has been carried out, yet this is critical regarding the Construction Products Directive (CPD; [17]) as from which emanates the need for research in the field of service life prediction and planning as to satisfy the requirements for Annex I [18]. Furthermore, knowledge is also required for product optimalisation. In order to do so, reliable data or methods must be delivered in order to gather knowledge concerning the moisture dynamics of plywood and the related time of wetness above certain moisture levels. Manual in-field gravimetric moisture pattern recording is stringent and very time consuming. Straightforward measurements with electrical moisture meters are excluded due to the influence of the layered set up, the presence of lathe checks due to veneer peeling, the compression during production and the glue lines on the measurement of the electric and dielectric properties [19].

To reduce the amount of work and to allow regular moisture measurements, a continuous moisture measurement (CMM) set up was developed based on recording of the voltage outputs of calibrated load cells while simultaneously weather data are also monitored. Recorded voltage data are converted to moisture content by using the calibration curve of the load cell and the oven dry weight of the plywood samples. Missing data are excluded and filtering is obligatory when dealing with large datasets to smoothen irregularities. The influence of different rain events is illustrated and correlation of weather data and moisture content profiles is presented, as well as further processing using different techniques. Finally, the CMM approach can also be used for time of wetness calculation of samples above certain moisture contents in a realistic outdoor exposure situation aiming at fast and easy comparison. Although this study is concentrating on plywood moisture related properties, the CMM is not exclusively developed for plywood since specimens of all other kinds of wood based panels can be easily fitted onto it.

\section{Material and methods}

\section{Test material}


The research presented in this paper is part of the work performed in a European Research Project called PLYBIOTEST. In this project a total of 60 different kinds of plywood produced by European plywood companies are tested for the biological performance in exterior out of ground application. For the purpose of this paper a selection is made of 10 not coated plywood types which can be regarded as typical plywood available on the European market (Table 1).

Table 1

\section{Preparation of the plywood specimens}

For a more detailed description of plywood preparation, the reader is referred to Van Acker and De Smet [2]. Briefly, the plywood specimen size $150 \times 150 \mathrm{~mm}$ and all edges of the test specimens were sealed. Subsequently, samples were conditioned before testing until constant mass in a conditioning room at $65 \% \mathrm{RH}$ and $20^{\circ} \mathrm{C}$. Plywood specimens were mounted on the load cells of the CMM set up with T-shaped holders. Initial moisture content of the test specimens had to be estimated by including 6 control specimens of $50 \times 50 \mathrm{~mm}$ for each plywood type to the conditioning process. These control specimens were weighed after constant mass was reached, oven dried $\left(103 \pm 2{ }^{\circ} \mathrm{C}\right)$ and weighed again, allowing the calculation of their initial moisture content according formula (1):

$$
\begin{gathered}
\theta_{c h}=\frac{m_{c h}-m_{0}}{m_{0}} \cdot 100 \\
\text { with } \theta_{c h}: \text { the moisture content }(\%) ; \\
m_{c h}: \text { the initial conditioned mass }(\mathrm{g}) ; \\
m_{0}: \text { the oven dry mass }(\mathrm{g}) .
\end{gathered}
$$

The oven dry mass of the CMM test specimens was estimated using the formula (2):

$$
m_{0}=\frac{m_{1}}{\left(\frac{\bar{\theta}_{c h}}{100}+1\right)}
$$


with $\bar{\theta}_{c h}$ : the mean moisture content of the control specimen (\%);

$m_{1}$ : the initial conditioned mass of the test specimen $(\mathrm{g})$;

$m_{0}$ : the oven dry mass of the test specimen $(\mathrm{g})$.

With $m_{0}$ known it is possible to recalculate the moisture content of the test specimens (in \%) at all logging moments using formula (3):

$\theta_{i}=\frac{m_{i}-m_{0}}{m_{0}} \cdot 100$

with $\theta_{i}$ : the moisture content of the test specimens at moment $i(\%)$;

$m_{i}$ : the mass of the test specimen at moment $i(\mathrm{~g})$;

$m_{0}$ : the estimated oven dry mass of the test specimen $(\mathrm{g})$.

To evaluate the effect of wind pressure and adhered rain drops on the plywood samples, several inert plates were mounted as well.

\section{CMM field test set up}

The CMM test set up consists of a wooden table upon which 2 parallel series of single load cells are fixed (Fig. 1).

Fig. 1.

Low profile single point load cells have a precision of $1 \mathrm{~g}$ and can weigh specimens up to 1000

g. Their aluminium alloy construction and their usable ambient temperature range from $-20^{\circ} \mathrm{C}$ up to $65^{\circ} \mathrm{C}$ makes them suitable for outdoor use. The load cells are mounted onto small inert plates adjustable with screws in the four corners for levelling. On top of the load cells aluminium Tshaped holders are fastened. 
The holders are bent at an angle of $45^{\circ}$ (Fig. 2). The table is facing south-southwest.

Fig. 2.

The load cells are fed with a recommended stabilised $10 \mathrm{~V}$ supply voltage with a response in the order of several $\mathrm{mV}$. Each load cell was calibrated individually in the range of 0 to $1000 \mathrm{~g}$. All load cells are connected to a weatherproof, rugged Delta-T DL2e data logging system. This system records the load cell responses with a logging interval of 1 minute. Every 5 minutes the mean is calculated and saved into a file. Adjacent to the CMM set up a fully equipped weather station is installed consisting of a solar radiation sensor, a tipping bucket rain gauge, a relative humidity probe, a thermometer, an anemometer and a wind vane. All weather data are collected by the same Delta-T DL2e logging unit with an interval of 5 minutes and included in the data file. When the maximum logging capacity is reached, the data are either uploaded manually to a portable computer or transmitted via a network connection to a central computer using a multiprotocol Black Box ${ }^{\circledR}$ device server.

\section{Data pre- and processing}

Missing data, probably due to malfunctioning equipment, were excluded from analysis. As data were logged every 5 minutes, this can result in unrealistic fluctuations, for example due to the accumulation of rain drops on the surface of the plywood. Therefore smoothing / averaging was performed to filter anomalies from the data profiles. Furthermore, the weight data of the inert plates were used to evaluate the effect of wind pressure. With the pre-processed recordings mean, median and standard deviations were calculated. Different rain event cases are discussed and frequency plots are examined. Time of wetness was calculated based on the number of days above the $20 \%$ and $25 \%$ moisture limits, which are used as guiding values for comparison of the different plywood types. At last, data were analyzed further by correlation and semblance analysis. 


\section{Results}

The CMM set up started running in June 2006. This study contains data of the first 300 days of exposure which are used to evaluate the usefulness of the set-up. Weather details as recorded during the 300 days period are presented in Table 2. Solar radiation is calculated over 24 hours.

Table 2

The original 5 minute data were converted to hourly means by averaging. To highlight different rain events, focus will be on the first months of exposure due to their uncommon character and the unweathered state of the samples at that time being. Especially June and July (month 1 and 2) have been exceptionally warm and dry compared to the average summer climate in Belgium, while August (month 3) was the wettest ever recorded.

Fig. 3 gives a graphical overview of a moisture content pattern together with data on the weathering parameters (rainfall, relative humidity $(\mathrm{RH})$ and temperature).

Fig. 3.

The influence of a rain event is clearly distinguishable, while also the daily recurrent pattern of $\mathrm{RH}$ and temperature is reflected in the plywood moisture content. Remark that the measurements are an average of the sample and do not give a decisive answer about the moisture distribution in the sample.

When taking a closer look at the mass changes of the inert samples (data not shown) the effect of wind is not univocal deducible. Moreover, the mass change of the inert sample, for example by accumulation of water on top of it, can not simply be subtracted from the plywood recordings as moisture on them can be absorbed by the top veneer, as such contributing to an increasing moisture content. Furthermore, the diurnal pattern is also observable on the inert samples, 
which can be attributed to the formation of a liquid layer during night, again with a different result on plywood samples. As the maximum change of mass on inert samples is on average $4 \%$ with only a minor estimated influence of wind, it can be stated that the measured voltages, once converted to meaningful moisture contents, are an accurate recording of the moisture dynamic of the plywood.

The obtained time series allow to investigate in detail the sorption reaction of different plywood types at defined rain events such as showers ( $<1 \mathrm{~h}$ of rain) followed by a dry period of several days (e.g. day 37-42), longer rain fall events with around 10h of rain (day 12) or long wet periods (e.g. month Augustus; days 60-90). Especially the dynamics during such events is interesting.

Case 1: short rain fall event or shower (week 7 - 14 July 2006)

The hourly mean MC patterns recorded during and after the reference shower are presented in Fig. 4a. Total rainfall was $8.2 \mathrm{~mm}$, average temperature $20.4 \pm 2.5^{\circ} \mathrm{C}$, average relative humidity $68.5 \pm 12.7 \%$ and total solar radiation $27.6 \mathrm{MJ} / \mathrm{m}^{2}$.

Fig. 4.

During the rain event an MC higher than $20 \%$ was recorded for plywood type p3 only. Quickly after the rain event the $\mathrm{MC}$ dropped beneath this limit. No other plywood samples reached the $20 \%$ level. As such during a shower only superficial wetting occurs. Therefore it is the outer veneer that determines the moisture accumulation. Plywood with thicker outer veneers reaches higher moisture content than the thin veneered variants (e.g. $\left.M C_{p 2}>M C_{p 1}\right)$. Although the b2 plywood has thick inner veneers, the outer veneer is merely $1.1 \mathrm{~mm}$, which can explain why for birch the maximum $\mathrm{MC}$ of thin veneered b1 type (outer veneer $1.4 \mathrm{~mm}$ ) is higher than for the b2 type. During very short rain events the influence of different glue types is minimal (e.g. p2 versus p3). 
Fig. $4 \mathrm{~b}$ illustrates the moisture reactivity of the plywood during the shower. The reactivity is obtained by normalizing the MC data. Normalization was done by dividing the hourly mean MCs during and after the shower by the mean $\mathrm{MC}$ level during the hour previous to the rain fall event. Fig. $4 \mathrm{~b}$ expresses clearly that the effect of a short rainfall event is not lasting longer than $30 \mathrm{~h}$ for all plywood types. Only $30 \mathrm{~h}$ after rain fall ceased the initial mean moisture content is reached and the daily recurrent pattern for plywood MC emerges again. While different maximum MC levels are reached, obviously an isolated summer shower is not capable of increasing the time of wetness for the entire sample above $20 \%$ substantially.

\section{Case 2: longer rain fall event (week 25 June -2 July 2006)}

The frequency and/or duration of the precipitation have a far greater impact on the plywood MC than the amount or intensity of precipitation. When a similar amount of precipitation as in case 1 is spread over a $13 \mathrm{~h}$ period, a clear distinction between different plywood specimens can be seen. Total rainfall was $11.4 \mathrm{~mm}$, average temperature $16.5 \pm 1.5^{\circ} \mathrm{C}$, average relative humidity $86.0 \pm 10.3 \%$ and total solar radiation $8.4 \mathrm{MJ} / \mathrm{m}^{2}$.Several plywood types surpass the $20 \% \mathrm{MC}$ limit for periods up to 1 day (Fig. 5a). The p3 plywood (thick veneered poplar plywood) stays above the limit for a period of $48 \mathrm{~h}$ while even reaching a $\mathrm{MC}$ more than $25 \%$ during one day.

\section{Fig. 5.}

It is remarkable that although there is a clear difference in maximum MCs reached during rainfall (between 14.84 and $31.58 \%$ ) the effect of the absorbed rain on the MC of plywood (Fig. $5 b)$ lasts approximately $84 \mathrm{~h}$ for all types. The more rain is absorbed the faster desorption takes place. Diurnal moisture patterns reappear after 72 hours. Sapelli and okoumé plywood are showing the smallest amount of reaction on rainfall while the p2 and p3 poplar plywood, the mp softwood plywood and the poplar-okoumé combination ok2 are more than doubling their MCs. Clearly, the originating wood species is the main parameter determining the moisture behaviour of plywood during a single rain event. Absorption tests in the lab indicated that birch solid wood 
is absorbing less moisture than poplar wood, while maritime pine and spruce are showing high levels of moisture absorption. Okoumé and sapelli proved to be least reactive. The same patterns are discernable in the outdoor exposure data for plywood (Fig. 5a).

Except for the originating wood species, glue type becomes a more decisive parameter for the moisture behaviour of plywood when considering longer periods of rainfall. PF-glued poplar plywood is absorbing more moisture than UMF-glued poplar plywood $\left(\mathrm{MC}_{\mathrm{p} 3}>\mathrm{MC}_{\mathrm{p} 2}\right)$. This suggests that although the PF glue line is acting as an initial moisture barrier, it allows moisture to pass when the period of rainfall is prolonged. Hypothesizing, it could be that a phenol formaldehyde glue line is more permeable for water than a ureum fortified melamine glue line, causing PF-glued plywood to accumulate more moisture and to desorb slower. When dealing with a wood species that is less reactive towards water absorption (e.g. okoumé), the glue-type is of minor importance.

Although the differences in maximum MC levels are increased, isolated rain events lasting less than 14 hours are not capable of increasing the moisture content permanently.

The different influence of rain intensity and rain frequency on plywood MC becomes clear when considering the hourly $\mathrm{MC}$ changes $\left(\mathrm{MC}_{\mathrm{t}+1}-\mathrm{MC}_{\mathrm{t}}\right)$ as shown in Fig. 6 for UMF-glued poplar plywood (p1).

Fig. 6.

Although the precipitation during the second part of the shower in case 1 was as intense as for the first part (3.8 $\mathrm{mm}$ and $4 \mathrm{~mm}$ ), almost no extra moisture absorption was achieved. The MClevel dropped immediately after rainfall ceased. Main desorption occurred in the first 9 hours after the shower. 16 hours after the shower the diurnal MC pattern re-emerges. In case 2 the most intense precipitation took place at hour $6(3.8 \mathrm{~mm})$, but the rise in plywood MC was not proportionally. The initial hour of rainfall caused the highest rise in MC (3.4\%), thereafter MC 
increased as long as the precipitation continued. Main desorption started 10 hours after it stopped raining. 48 hours after the start of the rain event the diurnal pattern emerges again. It is also interesting to notice the influence of windspeed and solar intensity, measured on a horizontal surface, on the moisture content during periods of zero rainfall in Fig. 7.

Fig. 7.

Absorption during the first rain event is not as high due to the solar intensity and wind. Clearly, desorption during the period $18-30$ hours is caused by the dehydrating action of the sun but especially by the increasing wind speed, as solar intensity is quite low. Therefore, when trying to accurately predict / interpret the moisture dynamics of plywood, it is obvious that both of these factors are also crucial in addition to precipitation during rainfall.

\section{Case 3: long wet period (August 2006)}

With $243.8 \mathrm{~mm}$ of rain August 2006 was the wettest August ever recorded in Belgian history. Precipitation was spread over 24 days with a peak precipitation of $60 \mathrm{~mm}$ on August the $25^{\text {th }}$. Mean air temperature was $17.5 \pm 2.9^{\circ} \mathrm{C}$ while mean relative humidity was $76 . \pm 14.0 \%$. The total solar radiation amounted up to $340 \mathrm{MJ} / \mathrm{m}^{2}$. Taking into consideration these climatic factors August 2006 can be regarded as an ideal outdoor climate for moisture accumulation and an increased risk on fungal growth. Fig. 8a shows the data for the month of August. Due to the prolonged period of rainfall, moisture accumulates and some plywood samples have not enough time to decrease their water content properly. Therefore the moisture content after each rain event is slightly higher than the previous one. Yet large fluctuations in moisture content can be observed (maxima ranging from $14.8-37.8 \%$ ).

Fig. 8. 
The overall ranking of plywood types according to their water absorption behaviour does not change. Poplar $\mathrm{p} 3$ and okoumé ok1 still mark the outer boundaries. Yet, the time of wetness above certain moisture limits becomes problematic for some of the plywood types. Due to their free hanging situation, wind and sun prevent moisture accumulation and contribute to fast desorption but this could not always be the case when built in. The ok1 remains well below the risk limits. The normalized values in Fig. 8b illustrate the enormous increase in MC for the thick poplar plywood p3 but as well for some other species.

The former detailed analyses show the close relation between rain events and absorption / desorption of moisture by plywood, the influence of different wood species and plywood types. However, for long time series analysis necessary to assess the time of wetness, it is difficult to analyze each rain event with that detail. The $20 \%$ an $25 \%$ moisture content limits are used as directional values for comparison of the different plywood types. Table 3 tabulates mean and median MC values and standard deviations, but more importantly the number of days on which the MC of the plywood test specimens, an average of all replicates per type, exceeded the MC limits during the first 300 days of exposure. Again, as the average of the sample's moisture content is used, it is not possible to pronounce upon the moisture distribution.

Table 3

Okoumé (ok1) and sapelli plywood (sap) are staying well below the limit of $25 \% \mathrm{MC}$, with ok1 reaching the $20 \%$ limit for only 9 days. Thin veneered poplar plywood ( $p 1)$ does not remain drier than the thick veneered variant (p2). Remarkably, they react quite well to weathering regarding the conclusions from the rain event analysis during the first three months of the CMM set-up. For birch the thin veneer plywood does absorb less moisture than the thick one (b1 and b2). This is different from what could be seen when analyzing a rain event. Clearly, absorption of moisture by the b2 plywood type increased at a certain time period without the possibility of desorbing properly. One could hypothesize that the moisture front has penetrated the glue line between the top and the second veneer just underneath the top one, resulting in a more 
permanent accumulation of moisture. A clear glue type effect can be noted for $\mathrm{p} 2$ and $\mathrm{p} 3$ plywood, where the PF glued type is exceeding $20 \%$ limit for 112 days while this is reduced to 69 days for the UMF glued poplar plywood. Softwood plywood ( $\mathrm{mp}$ and $\mathrm{sp}$ ) are very susceptible to moisture accumulation as well. Partially this can be explained by the thick outer veneers of the softwood plywood under test and by heavy cracking of the exposed outer veneer which was already visible after only one month of exposure. Standard deviations for these plywood types are high as well, indicating their reactive nature. The median MC provides a more nuanced view of the sorption behaviour since this value is less sensitive to peak $\mathrm{MC}$ values during heavy rain fall events. Clearly, differences are more or less the same as for the mean values.

Notwithstanding the influence of wood species, glue type and veneer thickness, one has to take into account the influence of weathering during the 10 months of recording. The increase in number of days above the $20 \%$ and $25 \%$ moisture limit is shown in Fig. 9.

Fig. 9.

Most interesting are the moisture dynamics of birch. The b2 plywood gives evidence of a steep increase in the number of days above $20 \%$ moisture content as from month 5 (Fig. 9a), passing maritime pine (mp), spruce (sp) and poplar (p3) after 9 months of outdoor exposure. Apparently, moisture accumulates and can not desorb from the sample. Yet, for 25\% MC (Fig. 9b), although manifesting a similar increase, it has not (yet) reached the values of the aforementioned plywood types. The PF-glued poplar p3 type seems to stabilize a little while being passed by several plywood types. Such long term dynamics are of utmost importance to assess the weathering resistance of the substrate under test.

Above-mentioned values are a first instigation to long term evaluation of plywood $\mathrm{MC}$ and the overall effect of outdoor ageing on the moisture dynamics. Histogram analysis as shown in Fig. 10 is another way to assess moisture dynamics for different plywood types. The two lines represent the critical $20 \%$ and $25 \%$ moisture content limits. They provide a means to visually assess a plywood sample very accurately. 
Fig. 10.

A clear feature of some plots is the emergence of a bimodal frequency pattern. Reason for this can be found in the division of the exposure period into a warm, dry summer period (June middle of October) and a colder and wetter winter (second part of October - March). The effect of difference in total thickness between 15mm and 18mm UMF glued poplar plywood ( $\mathrm{p} 1$ and p2) is small, both having a similar MC frequency plot. Glue-type is a more decisive parameter for the moisture behaviour of plywood. PF-glued 18mm thick poplar plywood (p3) is reaching very high MCs during several days while the UMF-glued variant remained drier, with more pronounced peaks around $10 \%$ (summer) and $18 \%$ (winter). The spruce (sp) and maritime pine (mp) plywood also exhibit a high absorption, whereas UMF-glued okoumé (ok1), to a lesser extend this holds for sapelli (sap) as well, stayed well beneath the moisture limits most of the time. From its frequency plot could be concluded that this plywood type has no MC values above the directional limits during the total exposure period. This has to be nuanced since one has to keep in mind that the MC measurement as obtained with the CMM set up is an MC for an entire plywood specimen. The $45^{\circ}$ test set up however induces an MC-gradient in the panels, with the veneers facing the rain having a higher MC than the veneers facing the ground. Remark that flat distributions point at highly reactive specimen, meaning that they exhibit large fluctuation in response to changing moisture climate, whereas sharp and narrow profiles are an indication of rather stable plywood with more or less fixed MCs within a certain range.

\section{Correlation analysis}

Whereas frequency plots give a useful overview of differing moisture behaviour, this kind of analyses cumulates every data point with an MC above a certain value. As such isolated periods in time with high MC are taken into account as well. The calculated amount of days is based on isolated as well as continuous time periods. Yet the richness of the data, taking into account the climate data, allows further analysis. As an example only unbroken series of high 
MC above a temperature minimum are considered. This can be interesting for the analysis of plywood samples regarding possible fungal growth, taking into account the constraint that the CMM set-up measures average moisture content of the entire sample which can deviate from local maximum moisture content. As an example the hourly means are used for calculation of the number of days where a certain $\mathrm{MC}$ and a temperature of $0^{\circ} \mathrm{C}$ is exceeded. Data were transferred to MATLAB $®$ for analysis. Fig. 11 displays the results of this kind of analysis.

Fig. 11.

Clearly, PF glued poplar (p3), spruce (sp) and maritime pine (mp) plywood remain wet for substantial time. Apparently, the thick birch plywood specimen retains its moisture for a long time within the $20-25 \%$ range, whereas the amount of days drops once exceeding $25 \%$ MC. This is opposite to what is found while analyzing the data of different rain events in the beginning of exposure, in fact before real weathering or moisture accumulation and penetration through barriers such as glue lines has taken place. Again, it is not surprising that the okoumé and sapelli specimen have a low curve profile, with okoumé almost never exceeding the $20 \%$ limit (curve equals $\mathrm{X}$-axis). The birch sample with thin top veneer exhibits a similar behaviour, meaning that from a high number of days at $20 \% \mathrm{MC}$ it drops rather towards $25 \% \mathrm{MC}$. The findings corroborate with previous analysis.

Obviously, rain events have an enormous influence on moisture accumulation, yet parameters such as solar intensity and wind speed might influence the drying of the sample and can substantially influence the moisture balance. Therefore the correlation between the numerical values of the moisture content of the plywood samples and the weather measurements can provide insight on their relation. It is not the purpose to aim at in-depth time series analysis, merely to illustrate some of the techniques that are available for time series research and that can be applied here. At first, straightforward correlation can be calculated. Coefficients are based on hourly data during 300 days and are given in Table 4 .

Table 4 
It should be mentioned that, obviously, the diurnal cycle has a large influence on the correlation data. Although not shown, all plywood profiles correlate logically extremely well. At first sight, it seems that especially relative humidity and temperature are strongest correlated with the moisture condition of the sample. Of course it should be remarked that both temperature and relative humidity are physically interrelated and related with solar radiation and rain events, but most important is the non-linear relation that exists between the measured weather data and the moisture conditions. For instance, a rain event of certain time (wavelength) and intensity (amplitude) has an impact on the moisture content of a plywood sample reacting on another time and intensity scale. Therefore it does not come as a surpise that rain events are poorly correlated to plywood moisture content, although a strong interrelationship is self-evident. In general a lag effect of the plywood material in response to the environmental conditions is natural. Some methods do include these non-linearities, such as wavelet-based semblance analysis [20], dynamic time warping (DTW, [21]) and longest sequence matching [22]. The last one is in fact a modification of dynamic time warping to obviate the drawback of outlier sensitivity and will not be explored here. Wavelet-based semblance is calculated as a function of both scale and time whereas this is not the case for Fourier-transform-based semblance analysis. Interpretation of semblance is complex. As an example, semblance between hourly scaled okoumé plywood MC data during approximately one month and several rain events is given in Fig. 12, as well as the two datasets.

Fig. 12.

The bottom figure is a visual representation of the similarities. The high red values indicate that the datasets are highly correlated at that position for that particular wavelength or time scale. As seen in the detailed analysis of several rain event cases, their influence reached further than the momentaneous character of the event itself with a high disturbance factor for the rain event in the middle of the time series. When doing the same for temperature and relative humidity, 
clearly, a wavelength of 24 hours with high correlation emerges, representing of course the diurnal cycle.

\section{Conclusions}

Continuous moisture measurements using calibrated load cells, a data logger and coupled with a weather station is an efficient way to handle moisture recording of all kinds of material, in this paper applied to plywood. Mean and median moisture contents are a first rank, but much more information can be extracted from the large datasets. Different rain events have a different impact on the plywood's moisture content. Showers or short rain events only cause superficial wetting and therefore the top veneer determines absorption and desorption rate. Although different maximum moisture percentages are reached, there is no moisture accumulation. Longer rain events have a longer impact and glue type becomes a more decisive parameter. It is hypothesized that the PF glue line is seemingly more permeable for water than the tested UMF glue line. Again, the directional value of $20 \%$ is exceeded but last only very short. Very long rain events however, such as the very wet month August during the summer of 2006 create ideal circumstances for moisture accumulation and clearly, the $25 \%$ value is exceeded during longer periods. Of utmost importance is the influence of continuous exposure on the moisture dynamics. Frequency plots point at the reactivity of the species and the exceeding of the $20 \%$ and $25 \%$ limits. The influence of natural weathering on the moisture dynamics of the samples was evaluated and pointed at the peculiar behaviour of birch plywood and the high moisture content of plywood made of maritime pine and spruce. At last, correlation analysis, ranging from standard correlation analysis to wavelet-based semblance analysis relates different climate parameters with plywood moisture content. Although the methods explored in this paper are only a pick of the various possibilities, they indicate the relation between environmental parameters and the moisture dynamics of different plywood types. Future research will concentrate on the possibility of predicting the behaviour of plywood based on environmental data and analysis of the recorded data after 2 years of outdoor exposure. The implementation of an engineering prediction tool based on neural nets is one of the lines of 
reasoning. Finally, a lab test is searched for that can mimic the outdoor process in order to predict moisture dynamics of different plywoods under natural weathering exposure. 


\section{Acknowledgements}

This research was performed in support of the European Research Project Biological performance testing methodology to evaluate the durability of plywood as a quality indicator for exterior construction purposes, with acronym Plybiotest (QLK5-CT-2002-1270). The authors would like to thank Mr. Rik De Rycke for his technical assistance. The authors also wish to thank the Fund for Scientific Research-Flanders (Belgium) for the postdoctoral funding granted to the first author. 


\section{References}

[1] Gustavsson L, Sathre R. Variability in energy and carbon dioxide balances of wood and concrete building materials. Building and Environment 2006;41(7): 940-951.

[2] Van Acker J, De Smet J. Moisture dynamics of plywood in exterior applications as a basis for service life prediction. In: Proceedings of the International Panel Products Symposium, Cardiff, South Wales, UK, 2007.

[3] EN 335, Hazard classes of wood and wood-based products against biological attack. European Committee for Standardization; 1996.

[4] EN 636, Plywood specifications. European Committee for Standardization; 2003.

[5] Dinwoodie JM. Timber: Its nature and behaviour. London: E \& FN Spon; 2000.

[6] Skaar C. Wood - water relations. Berlin: Springer-Verlag; 1988.

[7] Palka LC. A proposed model of the effect of moisture content on the mechanical properties of sheating-grade Douglas-fir plywood. In: Meyer R.W. editor. Structural use of wood in adverse environments. Van Nostrand Reinhold; 1982, p. 100-116.

[8] De Smet J, Van Acker J. Testing methodology and CE-marking for biological performance of plywood for exterior construction purposes. In: COST E44 and E49. Wood Resources and Panel Properties, Valencia, Spain, 2006.

[9] Rapp AO, Peek RD, Sailer M. Modelling the moisture induced risk of decay for treated and untreated wood above ground. Holzforschung 2000;54(2): 111-118.

[10] Viitanen H. Factors Affecting the Development of Biodeterioration in Wooden Constructions. Materials and Structures 1994;27(172): 483-493.

[11] Almgren KM, Akerholm M, Gamstedt EK, Salmen L, Lindstrom M. Effects of Moisture on Dynamic Mechanical Properties of Wood Fiber Composites Studied by Dynamic FT-IR Spectroscopy. Journal of Reinforced Plastics and Composites 2008;27(16-17): 1709-1721.

[12] Brischke C, Rapp AO, Bayerbach R. Measurement system for long-term recording of wood moisture content with internal conductively glued electrodes. Building and Environment 2008;43(10): 1566-1574. 
[13] Elowson T, Bergstrom M, Hamalainen M. Moisture dynamics in Norway spruce and Scots pine during outdoor exposure in relation to different surface treatments and handling conditions. Holzforschung 2003;57(2): 219-227.

[14] Hjort S. Full-scale method for testing moisture conditions in painted wood paneling. Journal of Coatings Technology 1996;68(856): 31-39.

[15] Lindegaard B, Morsing N. Service life prediction of wood claddings by in-situ measurement of wood moisture content. In: The Fifth International Woodcoatings Congress 'Enhancing service life', PRA Coatings Technology Center, Prague, Czech Republic, 2006.

[16] Pasanen AL, Rautiala S, Kasanen JP, Raunio P, Rantamaki J, Kalliokoski P. The relationship between measured moisture conditions and fungal concentrations in waterdamaged building materials. Indoor Air-International Journal of Indoor Air Quality and Climate 2000;10(2): 111-120.

[17] Council Directive of 21 December 1988 on the approximation of laws, regulations and administrative provisions of the member states relating to construction products (89/106/EEC). Council of the European Communities; 1988.

[18] Brischke C, Bayerbach R, Rapp AO. Decay-influencing factors: A basis for service life prediction of wood and wood-based products Wood Material Science and Engineering 2006;1(3\&4): 91-107.

[19] Torgovnikov GI. Dielectric properties of wood and wood-based materials. Berlin Heidelberg: Springer-Verlag; 1993.

[20] Cooper GRJ, Cowan DR. Comparing time series using wavelet-based semblance analysis. Computers \& Geosciences 2008;34(2): 95-102.

[21] Efrat A, Fan QF, Venkatasubramanian S. Curve matching, time warping, and light fields: New algorithms for computing similarity between curves. Journal of Mathematical Imaging and Vision 2007;27(3): 203-216.

[22] Vlachos M, Hadjieleftheriou M, Gunopulos D, Keogh E. Indexing multidimensional timeseries. Vldb Journal 2006;15(1): 1-20. 


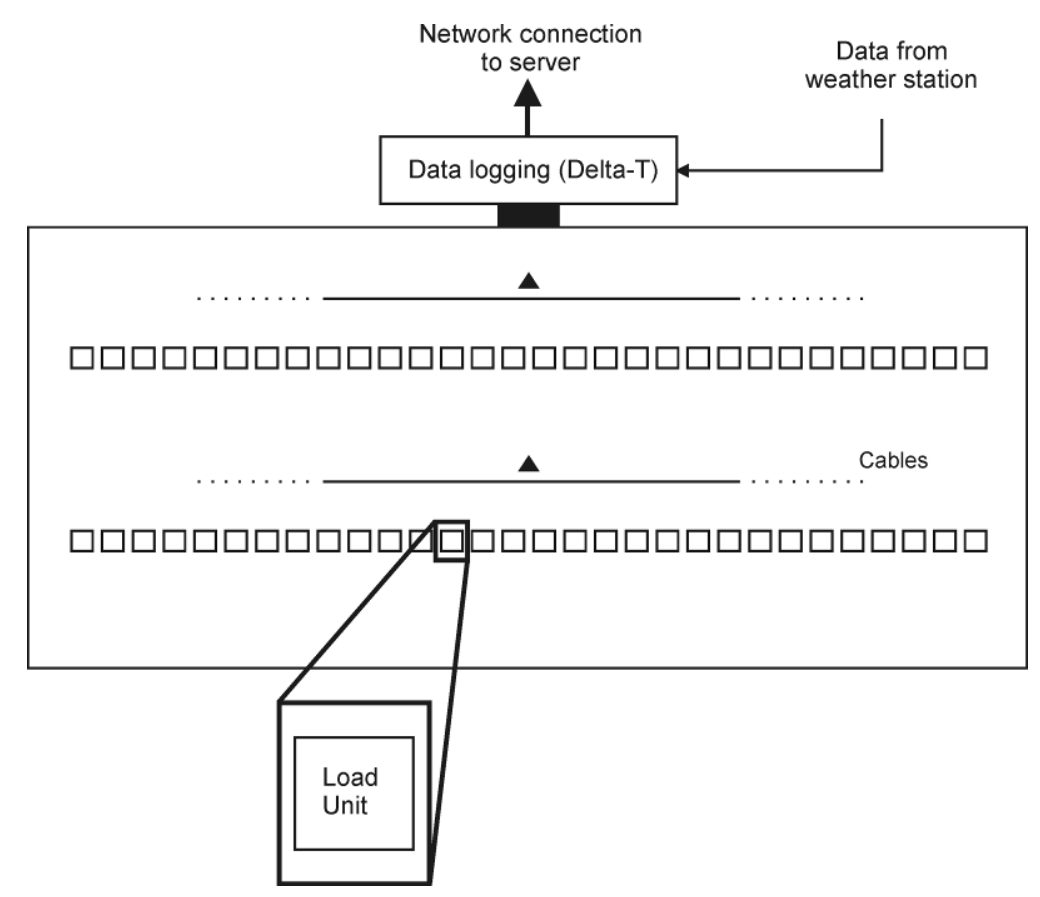

Fig. 1. Schematic overview of the continuous mass measurement (CMM) set up. 


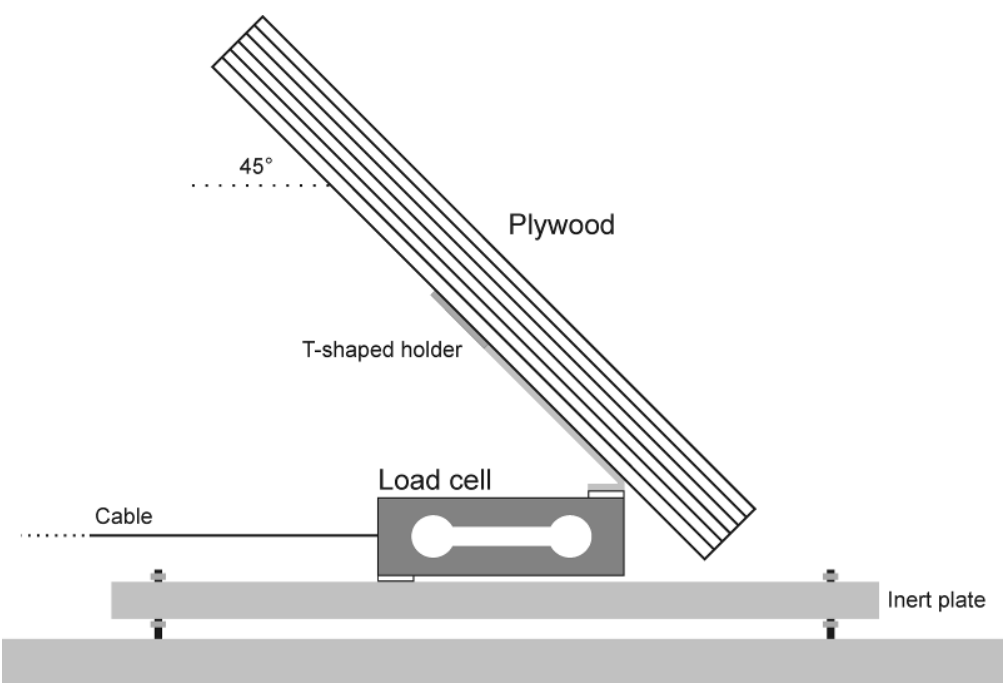

Fig. 2. Detailed view of a load unit. 


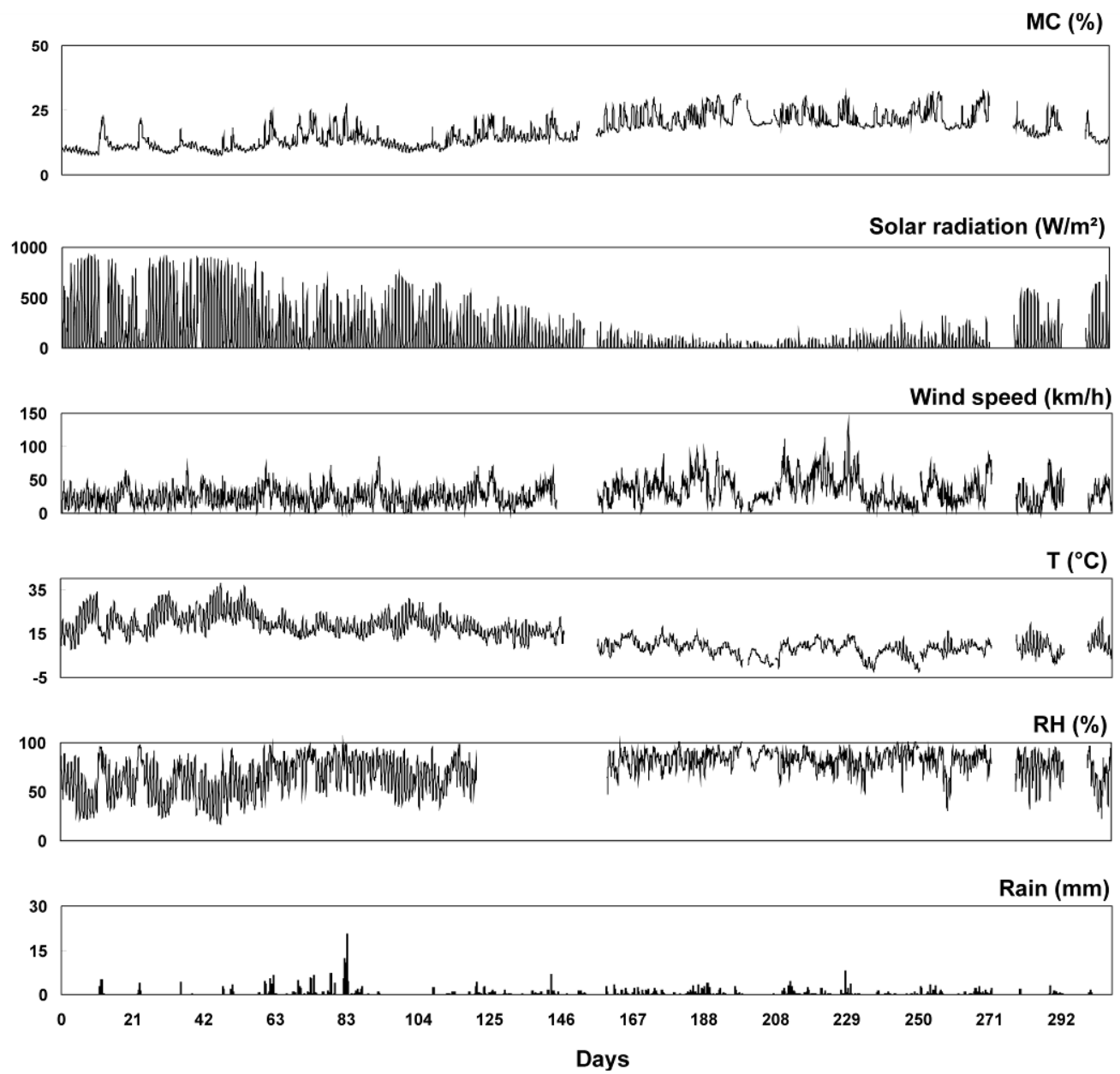

Fig. 3. Recorded moisture patterns and weather data during 300 days of outdoor exposure with the CMM (hourly data): (a) moisture content of poplar ( $\mathrm{p} 1$ ) plywood (\%); (b) relative humidity (\%); (c) temperature $\left({ }^{\circ} \mathrm{C}\right) ;(\mathrm{d})$ wind speed $(\mathrm{km} / \mathrm{h}) ;(\mathrm{e})$ average solar intensity $\left(\mathrm{W} / \mathrm{m}^{2}\right)$; (f) rain $(\mathrm{mm})$. 


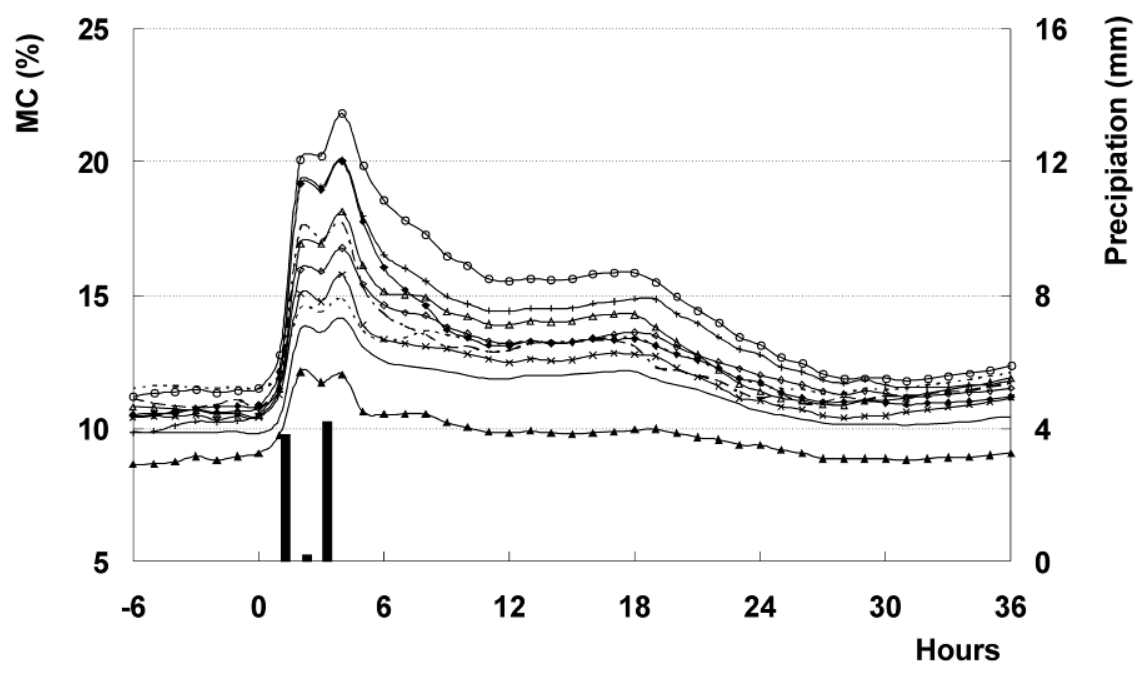

a

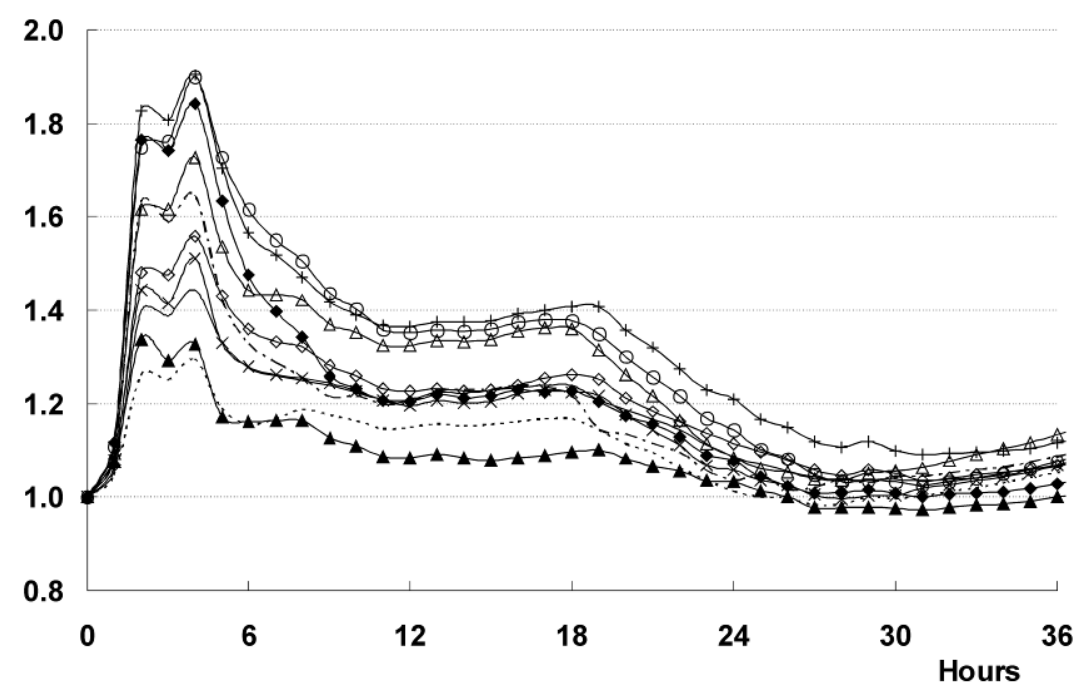

Fig. 4. (a) MC patterns of different outdoor exposed plywood types during an isolated shower event. Hourly mean MC data. Rain fall started at hour 1 ; (b) reactivity of plywood specimens: normalized data using hourly mean MCs. Normalization based on the hourly mean MC previous to the rainfall event. $\cdots=p 1, \bullet=p 2, \circ=p 3, \diamond=b 1,-=b 2, \Delta=s p, \Delta=$ ok1, $x=$ ok2, $---=$ sap, $+=\mathrm{mp}, \boldsymbol{\varpi}=$ precipitation . 

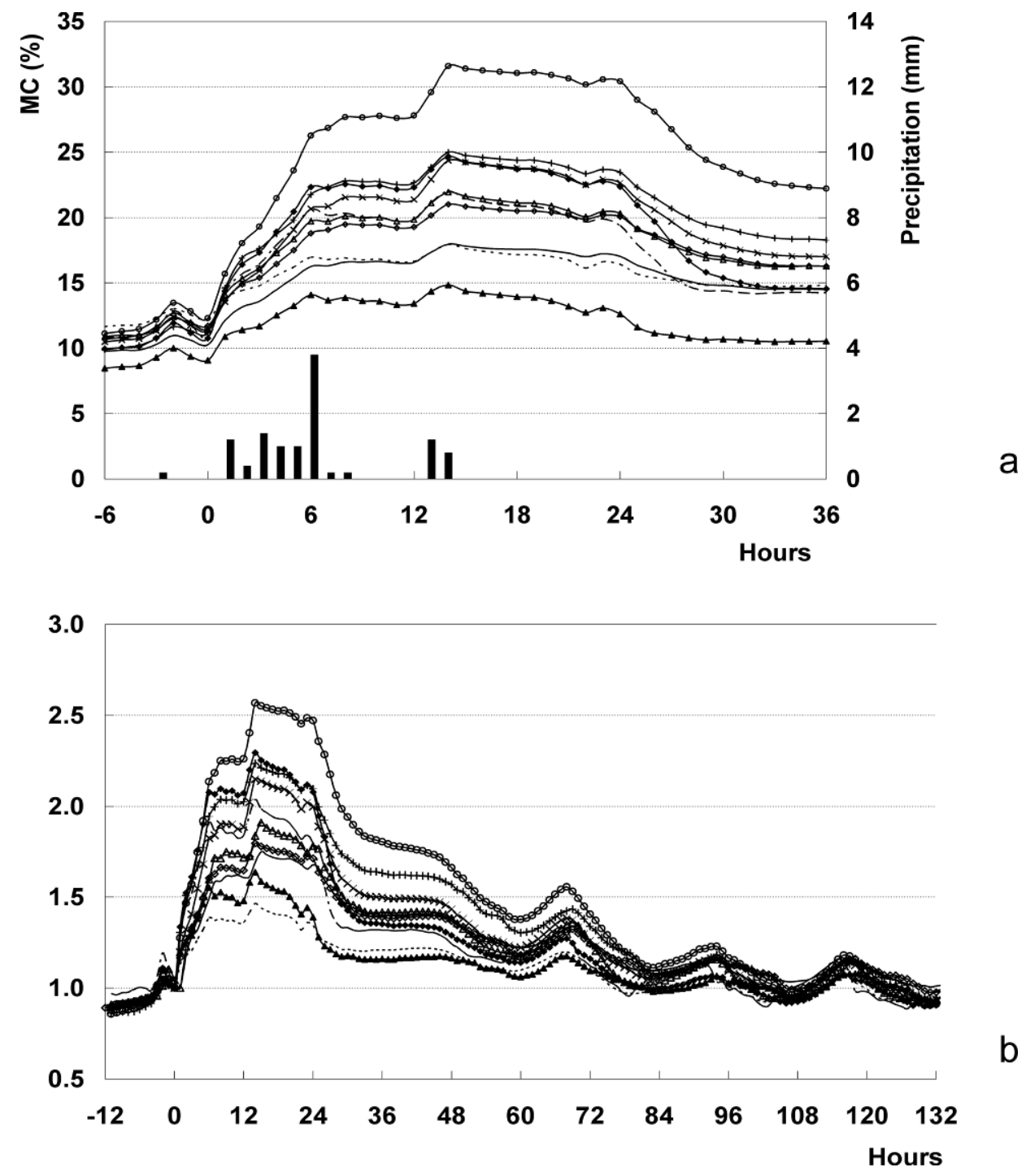

Fig. 5. (a) MC patterns of different outdoor exposed plywood types during a 13h rain event. Hourly mean MC data. Rain fall started at hour 1; (b) reactivity of the plywood specimens during a longer rain event: normalized data using hourly mean MCs. Normalization based on the hourly mean MC previous to the rainfall event. $\cdots=p 1,-p 2, \circ=p 3, \diamond=b 1,-=b 2, \Delta=s p, \Delta=$ ok1, $\mathrm{x}=$ ok2, --- = sap, $+=\mathrm{mp}, \boldsymbol{\square}=$ precipitation 

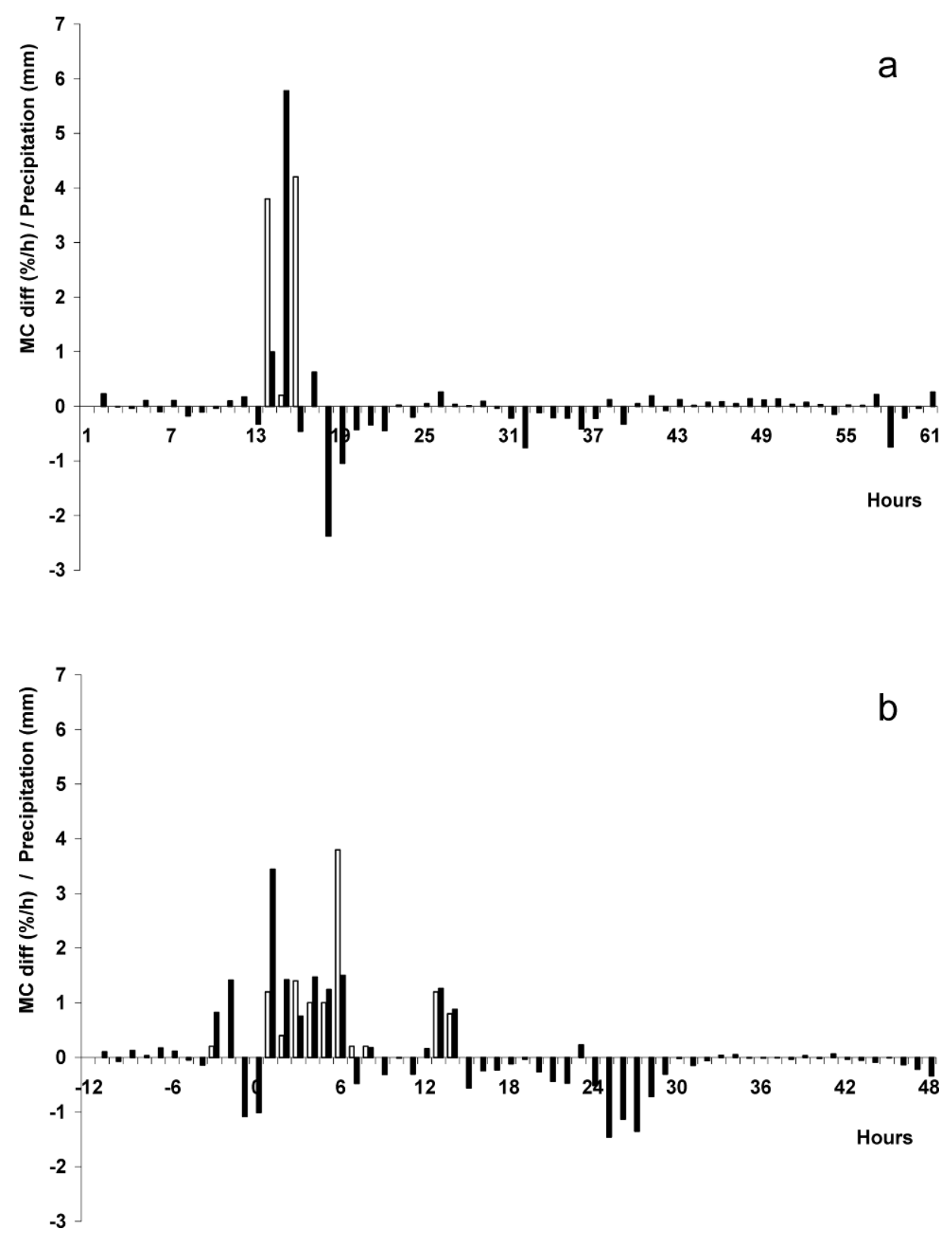

Fig. 6. Rainfall $(\mathrm{mm})$ and hourly $M C$ changes for UMF poplar plywood $\left(M_{t+1}-M C_{t}\right)(\% / h)$ in case 1 (a) and case 2 (b). Positive values indicate absorption, negative values desorption. $\square=$ Precipitation $(\mathrm{mm}), \boldsymbol{=}=\mathrm{MC}_{\text {diff }}(\mathrm{p} 1)$. 


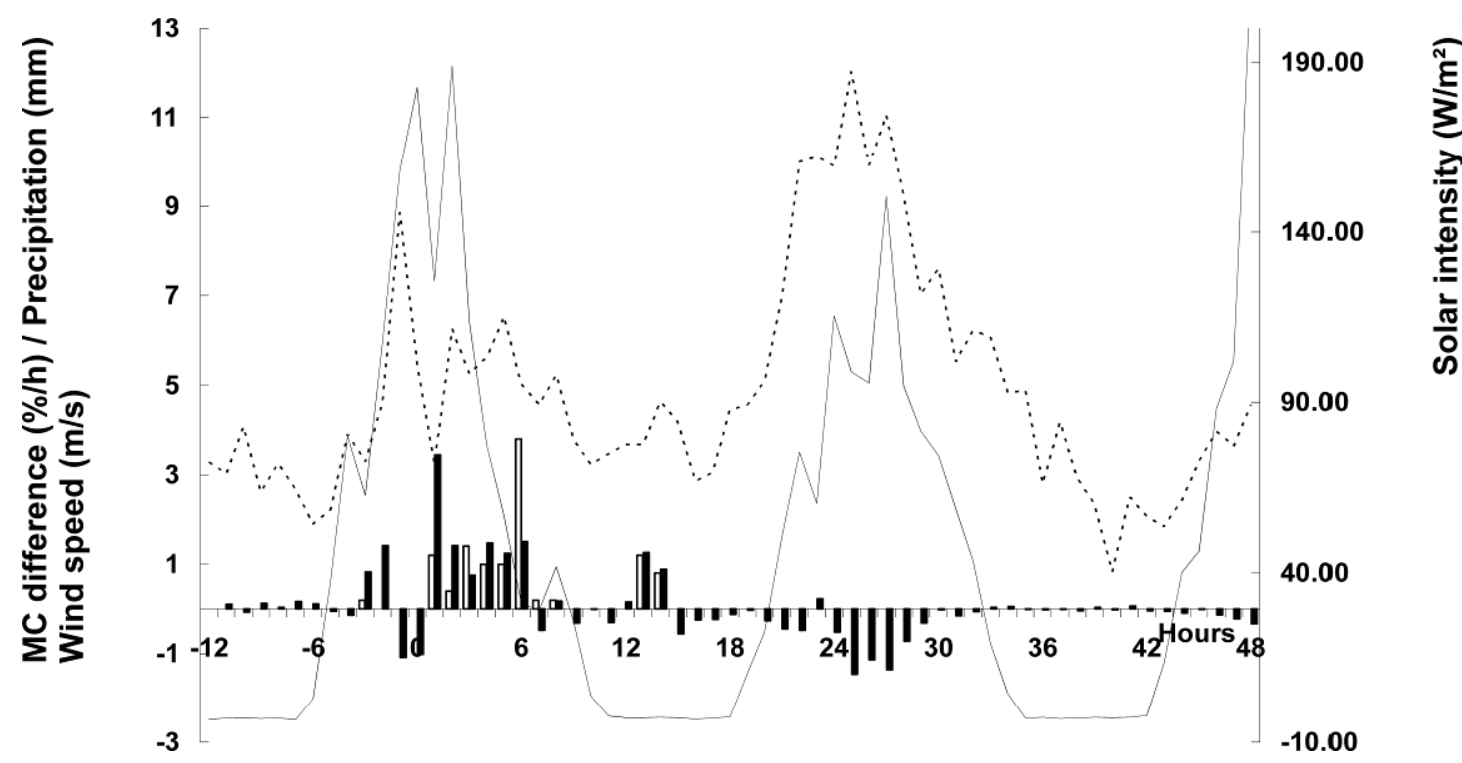

Fig. 7. The influence of wind speed (solid line) and solar intensity (dashed line) on the absorption / desorption behaviour of poplar plywood p1 during a moderate long rain event. 

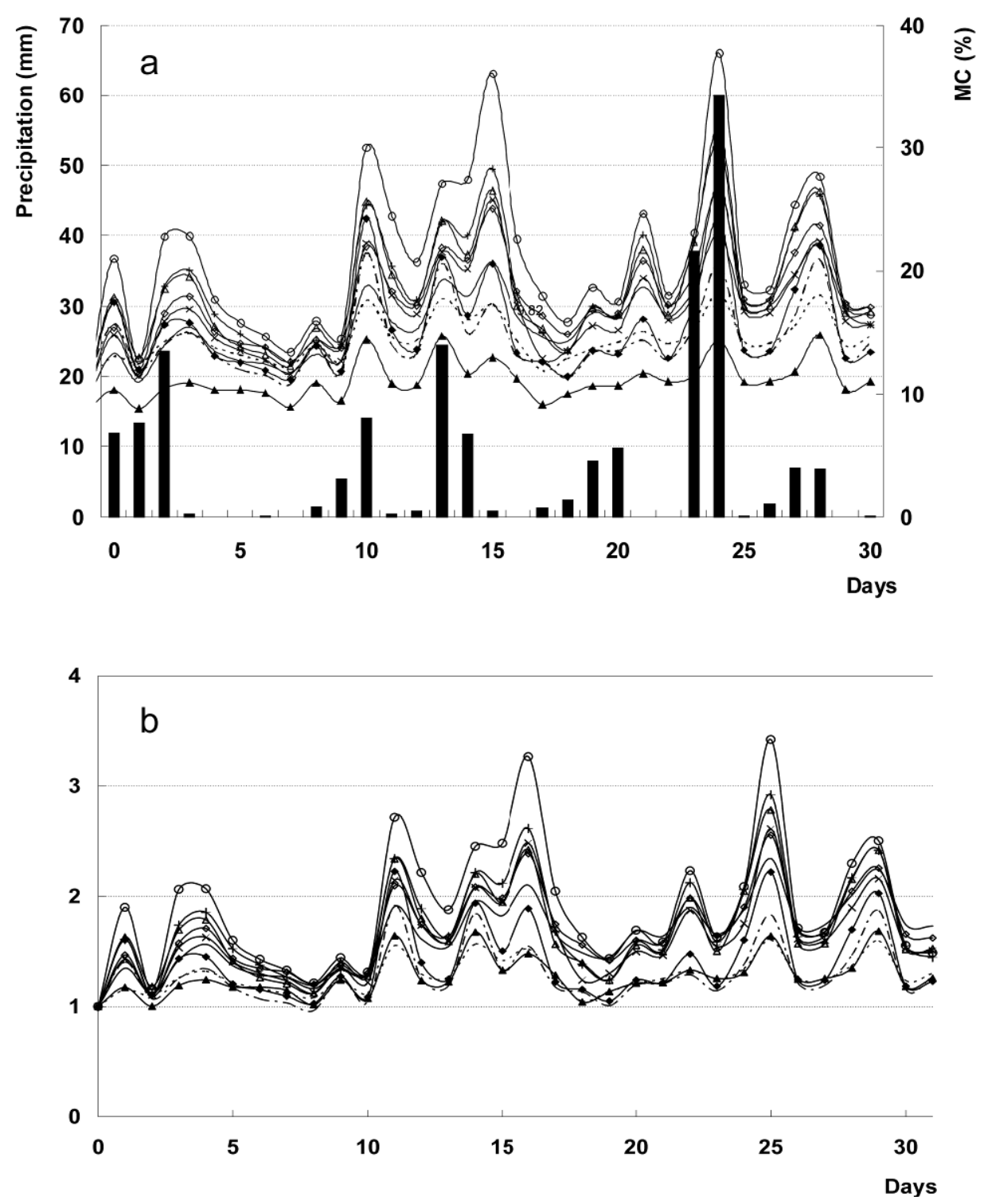

Fig. 8. (a) MC patterns of different outdoor exposed plywood types during 1 month (August 2006). Daily mean MC data; (b) reactivity of the plywood specimens: normalized data using hourly mean MCs. Normalization based on the hourly mean MC previous to the rainfall event. $\cdots=\mathrm{p} 1, \diamond=\mathrm{p} 2, \circ=\mathrm{p} 3, \diamond=\mathrm{b} 1,-=\mathrm{b} 2, \Delta=\mathrm{sp}, \boldsymbol{\Delta}=\mathrm{ok} 1, \mathrm{x}=\mathrm{ok} 2,---=\mathrm{sap},+=\mathrm{mp}$, precipitation. 

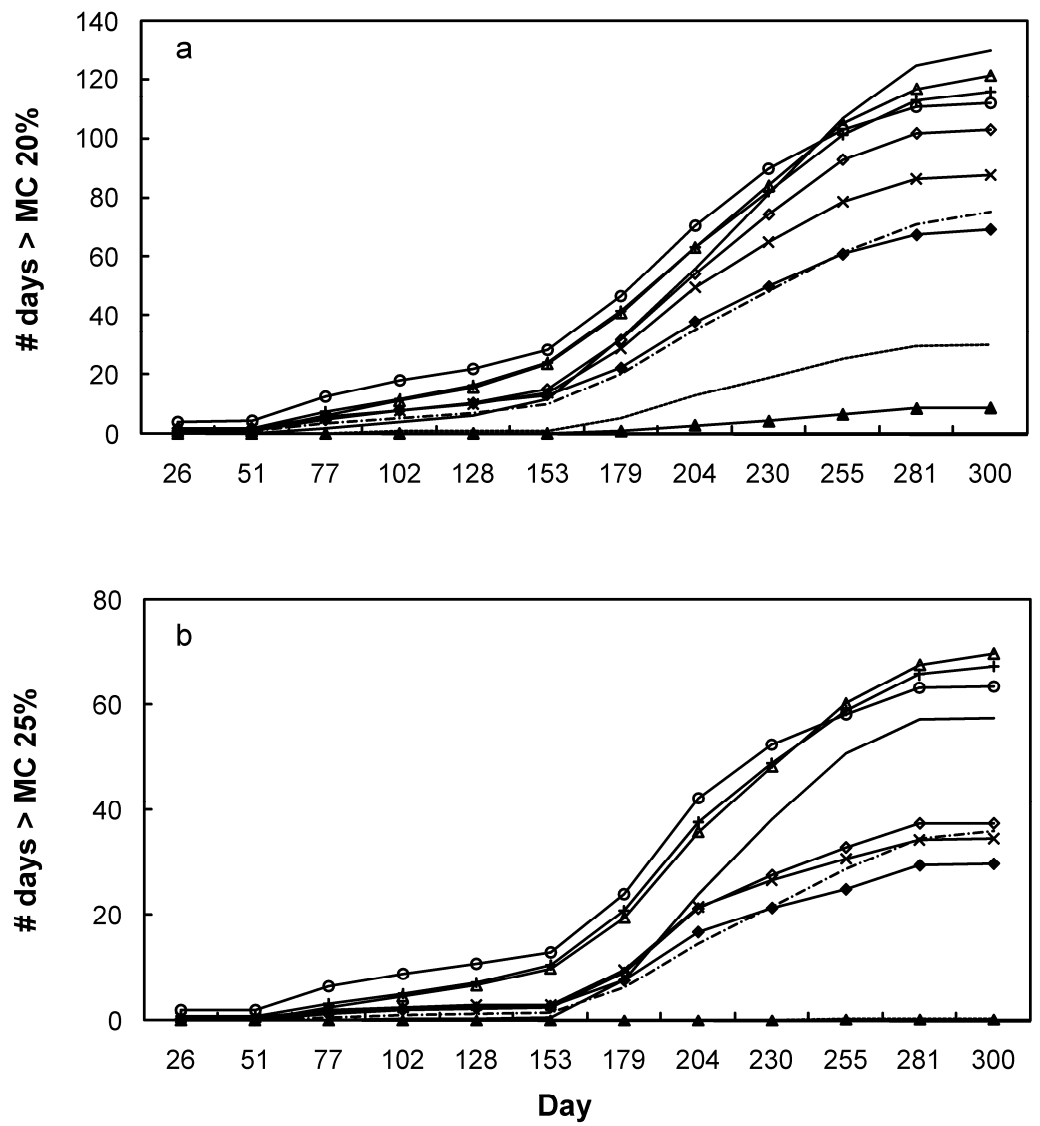

Fig. 9. (a) Number of days exceeding $20 \%$ moisture content in function of time; (b) number of days exceeding $25 \%$ moisture content in function of time. $\cdots=p 1, \downarrow=p 2, \circ=p 3, \diamond=b 1,-=$ b2, $\Delta=\mathrm{sp}, \boldsymbol{\Delta}=$ ok1, $\mathrm{x}=\mathrm{ok} 2,---=$ sap, $+=\mathrm{mp}, \boldsymbol{\boldsymbol { \sigma }}=$ precipitation. 

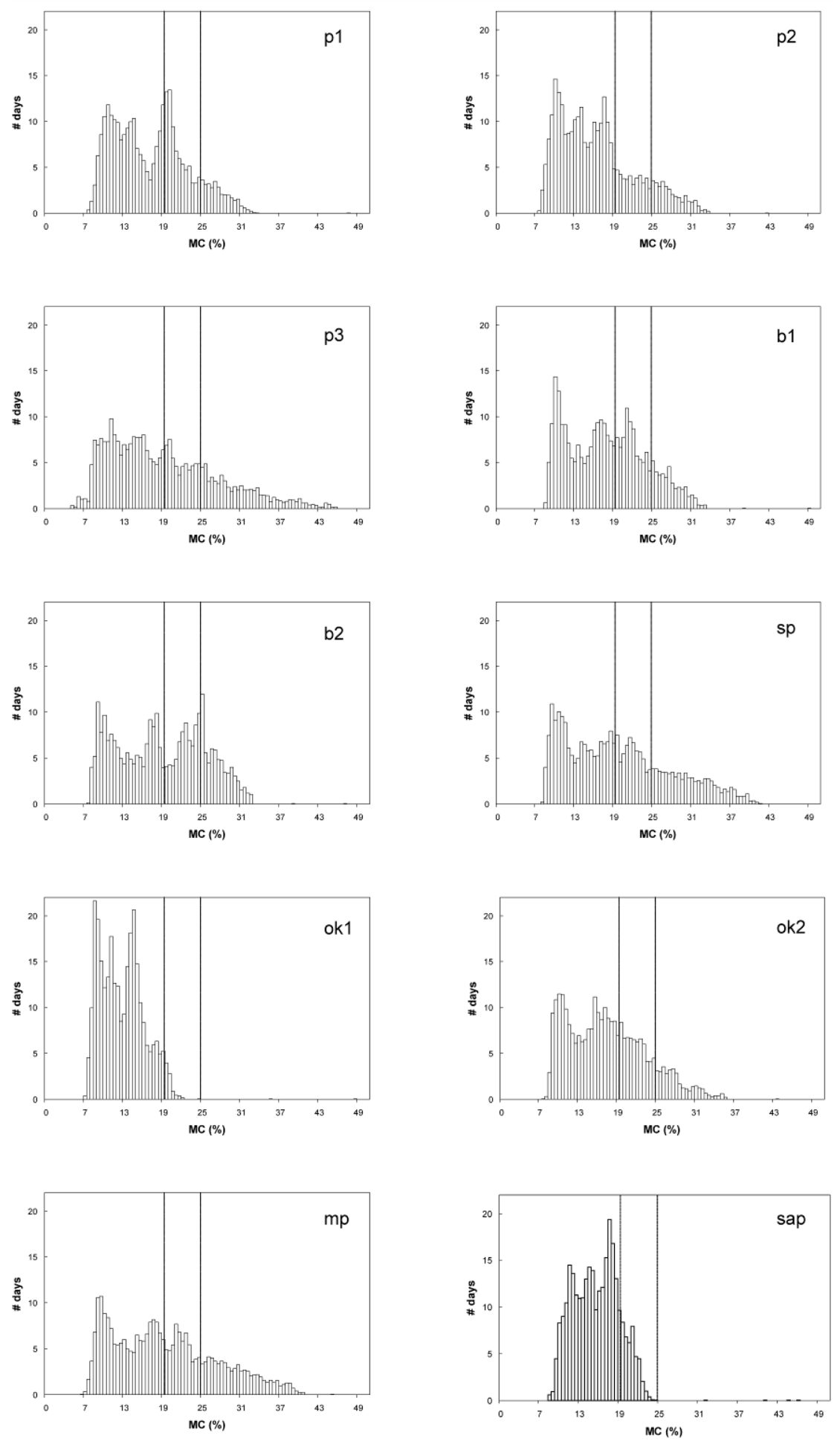

Fig. 10. Frequency plots during 300 days of exposure for the 10 plywood types with indication of the $20 \%$ and $25 \%$ moisture limits. 


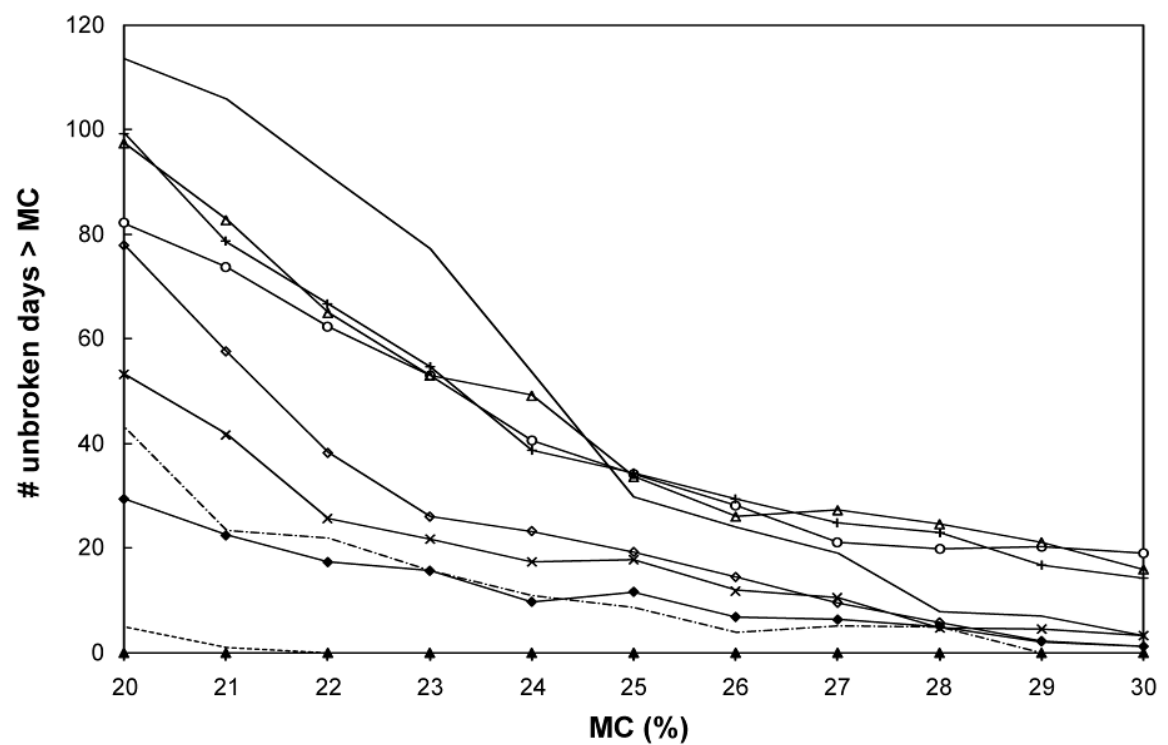

Fig. 11. Number of unbroken days $>$ certain moisture content. $\quad \cdots=p 1, \diamond=p 2, \circ=p 3, \diamond=$ $\mathrm{b} 1,-=\mathrm{b} 2, \Delta=\mathrm{sp}, \mathbf{\Delta}=\mathrm{ok} 1, \mathrm{x}=\mathrm{ok} 2,---=\mathrm{sap},+=\mathrm{mp}$. 

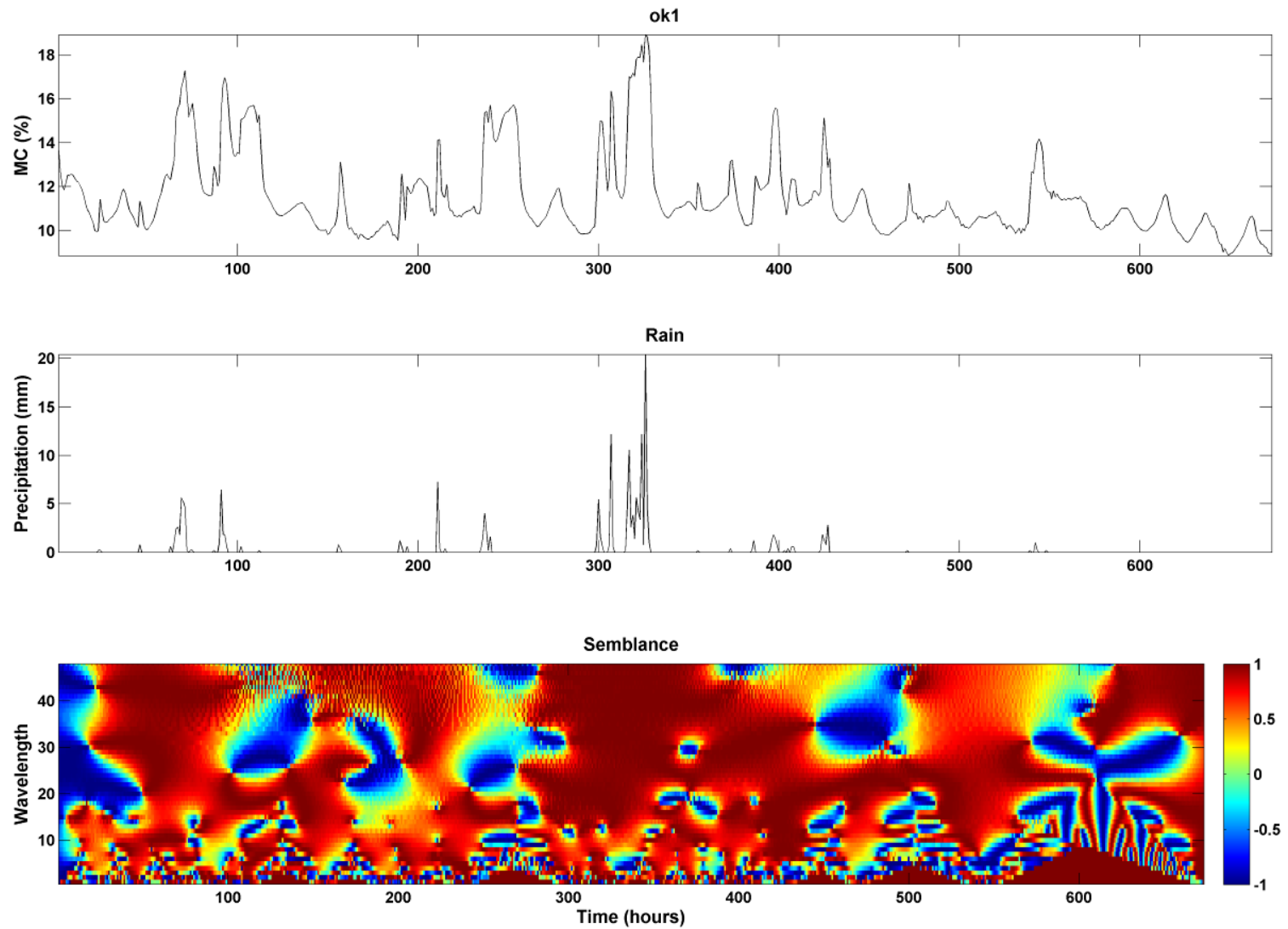

Fig. 12 Semblance between okoumé plywood moisture data and precipitation. 
Table 1

Plywood types used with details on wood species, glue type, veneer composition and number of replicates per veneer type

\begin{tabular}{lllllll}
\hline Code & Wood species & Glue $^{\mathbf{a}}$ & \# Plies & Thickness [mm] & Veneers $^{\text {b }}$ & \# Replicates $^{\text {2 }}$ \\
\hline p1 & poplar & UMF & 7 & 15 & $1.3 / 2.6 / 2.6$ & 4 \\
p2 & poplar & UMF & 9 & 18 & $2.1 / 2.1 / 2.1$ & 3 \\
p3 & poplar & PF & 9 & 18 & $2.1 / 2.1 / 2.1$ & 3 \\
b1 & birch & PF & 11 & 15 & $1.4 / 1.4 / 1.4$ & 6 \\
b2 & birch & PF & 10 & 20 & $1.1 / 2.3 / 2.3$ & 3 \\
sp & spruce & PF & 5 & 15 & $3.0 / 3.0 / 3.0$ & 6 \\
ok1 & okoumé & UMF & 7 & 15 & $1.0 / 3.0 / 2.0$ & 3 \\
ok2 & okoumé + poplar & PF & 7 & 15 & $1.0 / 3.0 / 2.0$ & 3 \\
mp & maritime pine & PF & 7 & 17 & $2.5 / 2.5 / 2.5$ & 3 \\
sap & sapelli & PF & 7 & 15 & $1.0 / 3.0 / 2.0$ & 3 \\
\hline
\end{tabular}

a PF: Phenol Formaldehyde glue / UMF: Ureum fortified Melamine Formaldehyde glue

${ }^{\mathrm{b}}$ Veneer thickness [mm]: top veneer / inner cross / inner core 
Table 2

Recorded weather data for the period June 2006 - April 2007

\begin{tabular}{lllll}
\hline & Mean & St. Dev. & Range & Cumulative \\
\hline Rain $[\mathrm{mm}]$ & 0.1 & 0.6 & $0-20.4$ & 730.4 \\
$\mathrm{RH}[\%]$ & 73.2 & 17.5 & $17.2-100$ & \\
Temperature $\left[{ }^{\circ} \mathrm{C}\right]$ & 14.0 & 7.1 & $-2.5-38.2$ & \\
Windspeed $[\mathrm{km} / \mathrm{h}]$ & 30.1 & 18.3 & $0-135.9$ & \\
Solar intensity $\left[\mathrm{W} / \mathrm{m}^{2}\right]$ & 101.2 & 190.3 & $0-929.8$ & $2.5\left[\mathrm{GJ} / \mathrm{m}^{2}\right]$ \\
\hline
\end{tabular}


Table 3

Mean and median MC values and standard deviations + number of days and standard deviation on which MC limits were exceeded during the first 300 days of outdoor exposure

\begin{tabular}{llllll}
\hline & MC [\%] & & & \multicolumn{3}{l}{$\mathbf{N}^{\circ}$ Days } \\
Code & Mean & St.Dev & Median & MC > 20\% & MC > 25\% \\
\hline p1 & 16.9 & 6.0 & 16.6 & 75 & 36 \\
p2 & 16.1 & 5.9 & 15.1 & 69 & 30 \\
p3 & 18.8 & 8.4 & 17.3 & 112 & 64 \\
b1 & 17.7 & 5.9 & 17.4 & 103 & 37 \\
b2 & 18.7 & 6.6 & 18.4 & 130 & 58 \\
sp & 19.5 & 8.1 & 18.5 & 121 & 70 \\
ok1 & 12.5 & 3.4 & 12.2 & 9 & 0 \\
ok2 & 17.1 & 6.1 & 16.6 & 88 & 35 \\
mp & 19.1 & 8.0 & 18.0 & 116 & 67 \\
sap & 15.3 & 3.5 & 15.3 & 30 & 0 \\
\hline
\end{tabular}


Table 4

Correlation analysis of plywood types and weather data: temp = temperature, windsp = windspeed, windir $=$ wind direction, solint $=$ solar radiation

\begin{tabular}{|c|c|c|c|c|c|c|}
\hline & rain & RH & temp & windsp & windir & solint \\
\hline p1 & 0.38 & 0.72 & -0.79 & 0.23 & -0.09 & -0.22 \\
\hline p2 & 0.39 & 0.68 & -0.70 & 0.23 & -0.08 & -0.17 \\
\hline p3 & 0.34 & 0.62 & -0.57 & 0.23 & -0.09 & -0.14 \\
\hline b1 & 0.33 & 0.63 & -0.67 & 0.26 & -0.09 & -0.14 \\
\hline b2 & 0.28 & 0.64 & -0.79 & 0.26 & -0.09 & -0.18 \\
\hline sp & 0.36 & 0.66 & -0.71 & 0.24 & -0.08 & -0.18 \\
\hline ok1 & 0.37 & 0.68 & -0.76 & 0.24 & -0.08 & -0.15 \\
\hline ok2 & 0.34 & 0.65 & -0.67 & 0.22 & -0.08 & -0.17 \\
\hline $\mathrm{mp}$ & 0.35 & 0.63 & -0.66 & 0.26 & -0.08 & -0.14 \\
\hline sap & 0.36 & 0.70 & -0.76 & 0.25 & -0.09 & -0.19 \\
\hline rain & & 0.29 & -0.12 & 0.16 & $-0.02^{a}$ & -0.04 \\
\hline $\mathbf{R H}$ & & & -0.65 & -0.07 & -0.09 & -0.37 \\
\hline temp & & & & $-0.02^{a}$ & 0.08 & 0.31 \\
\hline windsp & & & & & -0.10 & 0.30 \\
\hline windir & & & & & & 0.04 \\
\hline
\end{tabular}

${ }^{a}$ no significance 